\title{
Prediction of possible changes in glacio-hydrological characteristics under global warming: southeastern Alaska, U.S.A.
}

\author{
N. V. Davidovich and M. D. Ananicheva \\ Institute of Geography, Russian Academy of Sciences, Moscow 109017, Russia
}

\begin{abstract}
We use the Wetherald and Manabe climate model to predict the response of mountain glaciers to a doubling of atmospheric carbon dioxide. The response is measured in terms of a change in the equilibrium-line altitude (ELA) and the glacier terminus altitude (GTA), net accumulation-ablation on these altitudes and the melt runoff for 12 mountain-glacier regions in southeastern Alaska, U.S.A. The methods we use involve extrapolating climate-model temperature fields to a glacier's location, and empirical-statistical relationships between air temperature and percentage of solid precipitation, and between summer air temperature and ablation and melt runoff. Our study shows that, under global warming, glaciation in southeastern Alaska will not disappear, but mass exchange of glaciers will be more intensive and the ELA value will increase by $300-760 \mathrm{~m}$, depending on the glacier's distance from the ocean.
\end{abstract}

\section{INTRODUCTION}

Since all glaciers react to temperature changes, we became interested in foreseeing their future under a possible global temperature increase caused by growth of $\mathrm{CO}_{2}$ concentration in the atmosphere. If the present growth rate of carbon-fuel combustion is sustained, an anthropogenic warm spell is expected to continue for the first 50 years of the 21 st century.

To evaluate the degree of change associated with this possibility, we chose the southeastern part of Alaska, an area noted for the highest concentration of mountain glaciation in the temperate zone. This glaciation takes a wide variety of forms, the main ones being glacier fields, reticular mountain sheets and valley glaciers. We have already forecast (Ananicheva and Davidovich, 1993) the way Alaskan glaciers may respond to a global temperature increase in the early part of the 21 st century, using the M. Budyko model (Budyko and Israel, 1987). Here we attempt to predict glaciological processes in southeastern Alaska in the case of a doubled $\mathrm{CO}_{2}$ concentration $\left(2 \times \mathrm{CO}_{2}\right)$, expected to occur in the second half of the 21 st century.

\section{CLIMATIC SGENARIOS}

Of several existing climate-evolution scenarios we have chosen the one developed by Wetherald and Manabe (1988), the GFDL scenario (Geophysical Fluid Dynamics Laboratory of NOAA, Princeton). The reasons for this choice are that compared with other GCM Global Circulation Model) scenarios it pays regard to the largest number of variables, and that it seems especially suitable for regional applications because of a high degree of resolution, the data being on a related $4.5^{\circ}$ lat. $\times$ $7.5^{\circ}$ long. grid. The model gives output meteorological parameters for $1 \times \mathrm{CO}_{2}$ and $2 \times \mathrm{CO}_{2}$ situations; the former refers to the end of the $1950 \mathrm{~s}$ when the $\mathrm{CO}_{2}$ content in the atmosphere was measured. We also deal with observation and calculation data collected during the compilation of the World Snow and Ice Resources (WASIR) Atlas Kotlyakov, in press), and the data includes a period from the $1940 \mathrm{~s}$ to the $1970 \mathrm{~s}$, corresponding to the time of $1 \times \mathrm{CO}_{2}$.

The Wetherald and Manabe model, as well as other GCM models, gives mean monthly values of meteorological output data only at certain coordinate points, which means they are rather sparse, and nearly always fall on non-glacial areas. So we have to transform the scenario into isoline maps of the most important climatic parameters for both glaciation and melt runoff.

To solve the problem we use maps where temperatures are reduced to a certain constant level, for example sea level or a middle-of-mountain-region height. Such maps have been successfully used since the 19th century for investigation of climate-forming processes. For us they are the basis for another task: to determine spatial distribution of air temperature for mountain regions, characterized by a sparse meteorological-station network. In compiling such maps, we in no way substitute real mountains by plateaus. Since the altitude factor in the mountains is a leading one for air-temperature change, an exclusion of altitude reveals the remaining factors (specificities of atmosphere circulation, orography, glaciation, influence of neighboring seas and oceans, etc.) more distinctly. 
That is why the reduced maps automatically show changes of horizontal gradients in any direction. So we are able to extrapolate temperature values to any height with the help of the vertical gradient, and obtain vertical temperature profiles at any point within the area studied with minimized errors.

We averaged the Wetherald and Manabe scenario data for air temperatures to mean summer (June-August) values and then adjusted them to a constant altitude of $1000 \mathrm{~m}$ a.s.l. As a result we have compiled a series of maps for $1 \times \mathrm{CO}_{2}$ and $2 \times \mathrm{CO}_{2}$ situations and for the difference between them (Fig. 1). The adjustment is made with the help of vertical temperature gradients calculated over the temperature-altitude dependency: $T_{i}=f\left(H_{i}\right)$, where $T_{i}$ stands for mean multi-annual temperature of $i$ meteorological station, and $H_{i}$ for the meteorological station's elevation. For this purpose, data from 30 ground meteorological stations and four aerial stations in the U.S.A. and Canada within the whole period of observations are used.

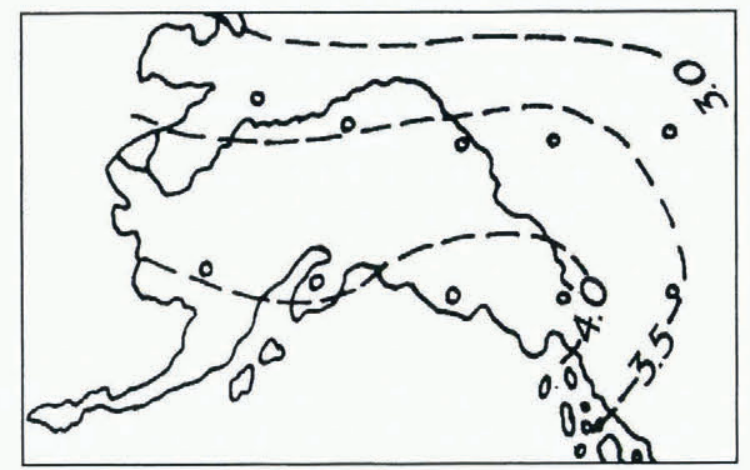

Fig. 1. Difference in $T_{\text {sum }}$ at 1000 ma.s.l. in the $1 \times \mathrm{CO}_{2}$ and $2 \times \mathrm{CO}_{2}$ situations. Circles show grid points of Wetherald and Manabe scenario.

In summer, the vertical temperature-gradient fluctuations decrease appreciably, which reduces errors to a minimum. For example the root-mean-square gradient deviation does not exceed $0.05^{\circ} \mathrm{C}$ per $100 \mathrm{~m}$ in the areas under Pacific Ocean influence, so when the difference in altitude is $1000 \mathrm{~m}$, errors in air-temperature determination by these gradients are no more than $0.5^{\circ} \mathrm{C}$. Average values of gradients were obtained separately for the areas of oceanic, continental and transitional climate types.

The average values obtained appear to be $0.5^{\circ} \mathrm{C}$ per $100 \mathrm{~m}$ in oceanic climate areas below $1500 \mathrm{~m}$ a.s.l., and $0.6^{\circ} \mathrm{C}$ per $100 \mathrm{~m}$ for those above this level. The equivalent values for gradient in continental climate areas are $0.6^{\circ}$ and $0.7^{\circ} \mathrm{C}$ per $100 \mathrm{~m}$. In transitional ones it is $0.6^{\circ} \mathrm{C}$ per $100 \mathrm{~m}$ for the whole altitude range (see footnotes to Table 1).

Figure 1 shows that, according to the Wetherald and Manabe scenario, the maximum growth of mean summer temperature $\left(T_{\text {sum }}\right)$ will increase southward in the direction of the Gulf of Alaska, i.e. the area of intensive cyclone activity and typical oceanic climate. The maximum increase of $T_{\text {sum }}$ (up to $4^{\circ} \mathrm{C}$ and more) occurs in the northeastern part of the Gulf and adjacent areas, i.e. where mountain glaciation is abundant.

As soon as we have the map of the $T_{\text {sum }}$ difference (Fig. 1), we can make vertical profiles of the predicted values of $T_{\text {sum }}$ at any point. Here we assumed that the vertical gradients of air temperature would not change from the $1 \times \mathrm{CO}_{2}$ situation, i.e., the changes in $T_{\text {sum }}$ remain the same within the whole lower layer of the troposphere.

Along with air temperature, the amount of solid precipitation is one of the principal parameters determining glacier regime and melt runoff. However, the Wetherald and Manabe scenario outputs total precipitation. All the existing methods of calculating solid precipitation are based upon the relationship between solid precipitation and air temperature. Unfortunately, most of those methods are applicable only in certain regions; for example, the well-known Cehak-Trock (1958) formula was derived from data obtained in Western Europe and could not be applied to other physicalgeographical conditions since it was developed regardless of the climate's continentality/oceanity degree, topography and elevation. These factors are considered in the method proposed by Bogdanova (1976). This uses longterm empirical data on monthly correlations between proportions and amounts of difference types of precipitation as they vary with altitude level, mean monthly air temperatures and continentality/oceanity degree. The method is developed on all available meteorological observations in various physical-geographical regions (the data for mountain regions, obtained at 65 stations above $1000 \mathrm{~m}$ a.s.l.). Proposed general (not related to specific locations) dependency enables a monthly and subsequently annual value of solid precipitation to be calculated. Using this method, the rms deviations between actual and calculated solid-precipitation proportion equal $10 \%$ for a month and $5 \%$ for a year.

Applying Bogdanova's (1976) method, we have obtained annual solid precipitation $\left(X_{\text {sol }}\right)$ for every grid point of the studied area for the $1 \times \mathrm{CO}_{2}$ and $2 \times \mathrm{CO}_{2}$ situations and then compiled a map of their ratio (Fig. 2). Unlike total precipitation which, according to theWetherald and Manabe scenario, tends to increase 1.2 1.3 times when $\mathrm{CO}_{2}$ content doubles, $X_{\text {sol }}$ remains almost stable within the studied area, except for the Alaska Range and areas north of it, where $X_{\text {sol }}$ increases 1.1 times. The map shown in Figure 2 and modern empirical vertical profiles of $X_{\mathrm{sol}}$ make it possible to design vertical profiles of the predicted $X_{\mathrm{sol}}$ values (assuming that the relative change of $X_{\mathrm{sol}}$ in the $2 \times \mathrm{CO}_{2}$ situation remains the same within the whole lower layer of the troposphere).

We have singled out 12 mountain-glacier basins characterized by specific climate and glaciation types, in

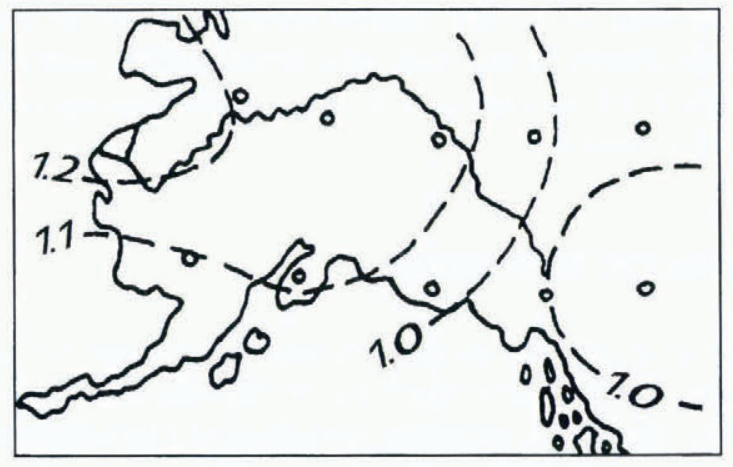

Fig. 2. The ratio between $\mathrm{X}_{\mathrm{sol}}$ in the $\mathrm{I} \times \mathrm{CO}_{2}$ and $2 \times \mathrm{CO}_{2}$ situations. 
southeastern Alaska. Vertical profiles of $T_{\text {sum }}$ and $X_{\text {sol }}$ averaged over each basin were drawn for both the $1 \times$ $\mathrm{CO}_{2}$ and $2 \times \mathrm{CO}_{2}$ situations. These are necessary for the subsequent calculations.

\section{SCENARIO TRANSFORMATION FOR GLACIER SURFACE}

Since meteorological parameters in mountain regions are greatly influenced by glaciers, the next phase of our study includes calculations and graph implementation of vertical profiles of the $T_{\text {sum }}$ and $X_{\text {sol }}$ over the glaciers. In summer, the glaciers cool the air above. This cooling effect is caused mainly by turbulent heat exchange with the melting snow/ice surfaces. The values of $T_{\text {sum }}$ over glaciers have been obtained in accordance with the method proposed by Davidovich (1983). Its general theoretical scheme is shown in Figure 3. The degree of cooling effect can be estimated by the difference in air temperature between a glacier and ice-free surfaces at the same altitude. This difference, called the "temperature leap" $(\Delta t)$, varies within the territory of a glacier and reaches its maximum in the upper section of the ablation zone, in the area of the equilibrium-line altitude (ELA). The glacier cooling effect vanishes in high elevated areas where air temperature is constantly below zero. Here there is no significant difference in air temperature between glaciers and ice-free surfaces. There are no positive mean daily temperatures in the case of $T_{\text {sum }} \approx$ $-4 \mathrm{C}$. Here the $\Delta t$ actually disappears. In glacieradjacent territories, only the areas of glacier wind extent, i.e. heads of glacial valleys, are subject to the cooling effect of glaciers. The glacier terminus belt is influenced by both glacier and valley winds, which is why this belt slightly differs in air temperature from that of neighboring ice-free territories.

At present we have no reliable approach to calculate temperatures on unexplored glaciers. The "temperatureleap" value depends upon a broad range of factors which we are unable to consider in the proper way. However, direct temperature observations on smaller and mediumsize glaciers (areas not exceeding $40 \mathrm{~km}^{2}$ ) within the temperate zone show a considerable correlation between temperatures above glacial and ice-free surfaces at the ELA. Data collected by a number of glaciological

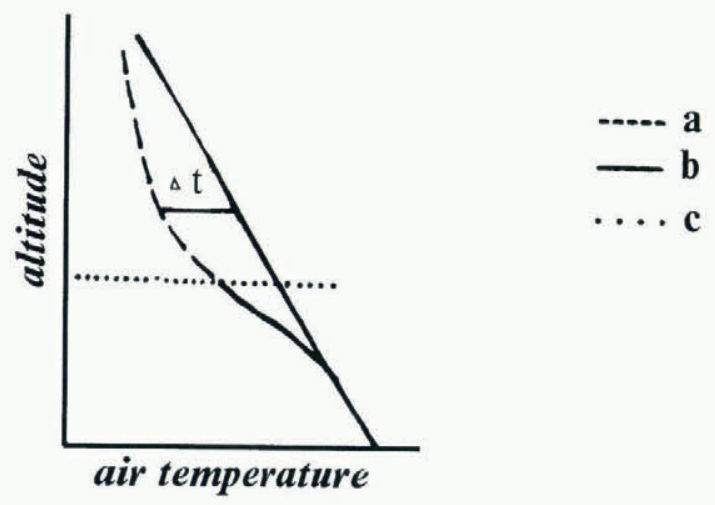

Fig. 3. Change of air temperature us altitude of a mountain-glacier basin: $a$, over glacier surface; $b$, over non-glacier surface, ( $\Delta t$ temperature leap); $c$, glacier terminus altitude. expeditions to the Caucasus, Pamirs, Tien Shan, Altay and Scandinavian mountains (observations embracing a total of 33 summer seasons) have been reviewed. The correlation between the glacier temperature $\left(T_{\mathrm{g}}\right)$ and non-glacier temperature $\left(T_{\mathrm{ng}}\right)$ in the area of the ELA was obtained, and turned out to be statistically significant. The dependency derived is described by a regression equation as follows:

$$
T_{\mathrm{g}}=0.85 T_{\mathrm{ng}}-1.20 .
$$

The correlation coefficient is $0.90 \pm 0.03$; the mean square error is $\pm 0.6^{\circ} \mathrm{C}$ (Davidovich, 1984). Using Equation (1) we have computed $T_{\mathrm{g}}$ at the ELA for each of the 12 basins selected. We chose the $\Delta t$ to be equal to $0.2^{\circ} \mathrm{C}$ on the glacier termini. Above the ELA the $T_{\mathrm{g}}$ profile can be extrapolated to the height where $T_{\text {ng }}$ reaches $-4^{\circ} \mathrm{C}$.

Since Equation (1) is valid for glaciers not exceeding $40 \mathrm{~km}^{2}$ in area and we have applied it to all glacier types, we are likely to have exaggerated the $T_{\mathrm{g}}$ values for the Juneau and Fairwater glacial fields. Evidently, the $\Delta t$ over large glacial fields is greater than over mountainvalley glaciers. However, this problem has not been explored.

\section{GLACIOLOGICAL FORECAST}

Having evaluated $T_{\text {sum }}$ and $X_{\text {sol }}$ for glaciers in all basins, we can turn to the main task of this paper, an estimation of the components of glacier mass exchange under the global temperature increase $\left(2 \times \mathrm{CO}_{2}\right.$ situation). To determine an ablation $(\mathrm{Abl})$ we have applied the formula of Krenke and Khodakov (1966), as updated in 1980:

$$
\mathrm{Abl}=1.33\left(T_{\text {sum }}+9.66\right)^{2.85} .
$$

The formula chosen surpasses other approaches since it is based upon worldwide data on different physical geographical conditions of polar and temperate latitudes, and deals with temperature, a parameter which is the most precisely defined and most suitable for vertical and horizontal extra- and interpolation.

To calculate accumulation (Acc) we have applied different approaches to different glaciation types. For glacier fields, Acc has been assumed to be equal to $X_{\text {sol }}$. On mountain-valley glaciers, snow-cover depth is more than $X_{\text {sol }}$ of the surrounding areas due to snowdrifting and avalanches. That is why we increase $X_{\text {sol }}$ by the coefficient of snow concentration. The latter we calculate as a ratio between Acc at the ELA (taken from the WASIR (Kotlyakov, in press) glaciation-regime map) and $X_{\text {sol }}$ (defined by the vertical profiles) for the same elevations. It averages $1.2-1.4$ in different basins. The intersection of the Abl and Acc profiles (Fig. 4) enables us to determine the ELA and estimate the mass-exchange components for this glacial level in the $2 \times \mathrm{CO}_{2}$ situation (see Table 1; Fig. 4).

Besides the ELA, it is important to evaluate the behavior of the glacier termini for a more comprehensive picture of the glaciation change. The glacier terminus altitude (GTA) tends to be more sensitive than the ELA 


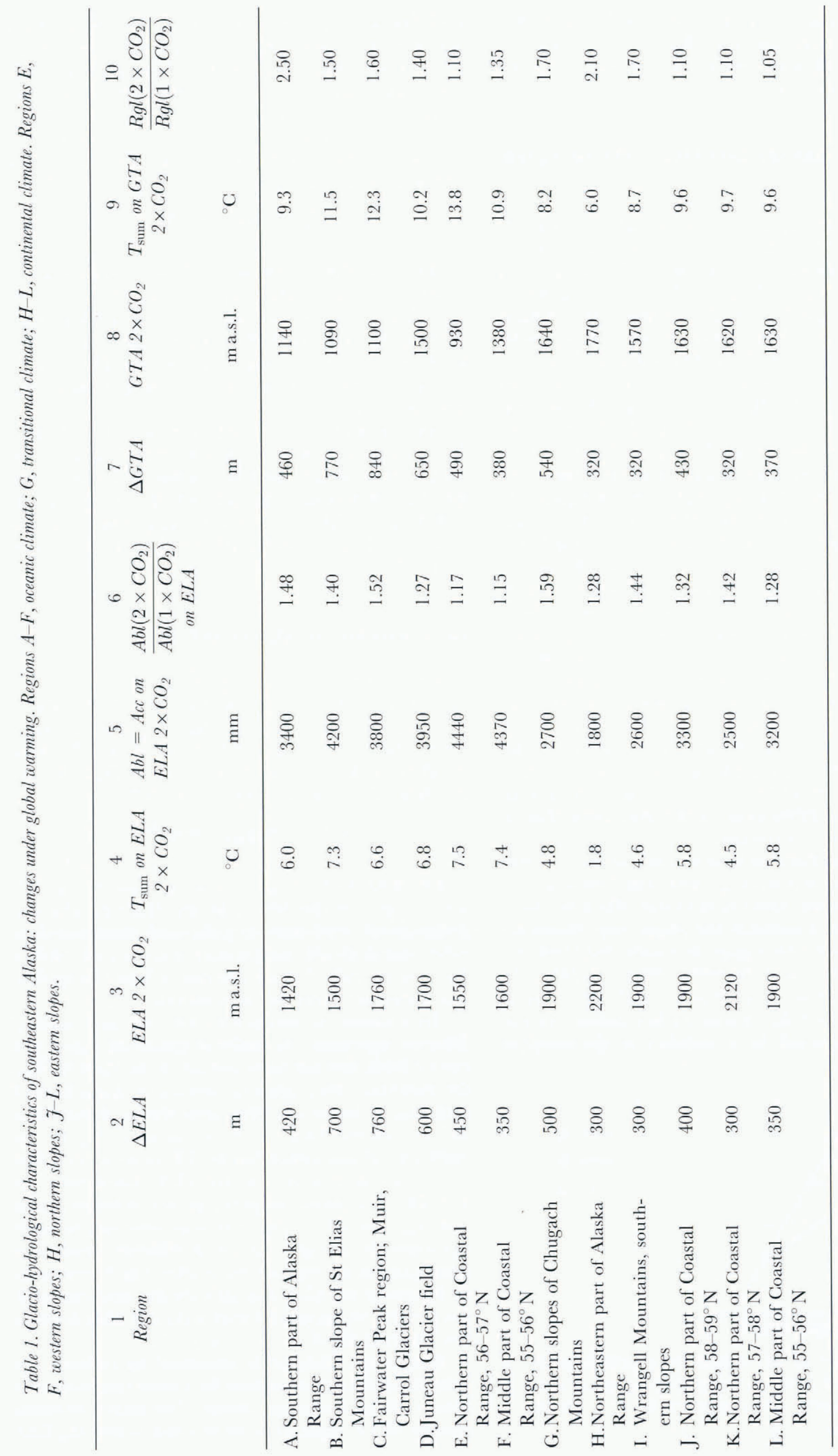



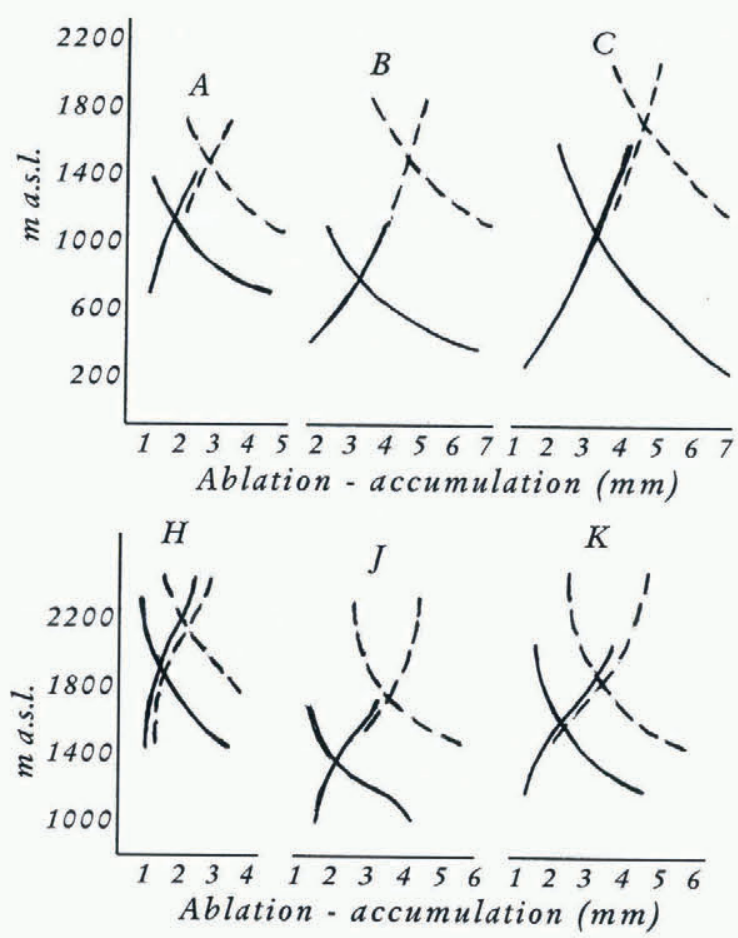

Fig. 4. Examples of vertical ablation and accumulation distribution for oceanic regions $(A, B, C)$ and continental ones $(\mathrm{H}, \mathrm{J}, \mathrm{K})$ for the $1 \times \mathrm{CO}_{2}$ (solid line) and $2 \times \mathrm{CO}_{2}$ (broken line) siluations.

to climate change, particularly air temperature. So we assume that the GTA would change only under the influence of temperature variations, and that the $1 \times \mathrm{CO}_{2}$ temperature at the glacier terminus would not change in the $2 \times \mathrm{CO}_{2}$ situation at a new altitude. Under that assumption we determine the new terminus altitude (see example in Figure 5). Then we calculate the $\Delta$ GTA/ $\Delta$ ELA ratio. This turns out, as we might expect, to be a bit more in the oceanic climate regions $(1.10)$ than in continental ones (1.07). Mean GTA in the $1 \times \mathrm{CO}_{2}$ situation is derived from topographic maps compiled in the middle of the 20th century. However, the new values should be considered as a first approximation, because we have taken into account only a temperature factor.

Table 1 and Figures 6 and 7 show that, in accordance with the Wetherald and Manabe scenario, the GTA and ELA will be considerably displaced upward, resulting in a relatively strong increase of $T_{\text {sum }}$ and a negligible change of $X_{\mathrm{sol}}$. Thus, the maximum change of these glacier levels

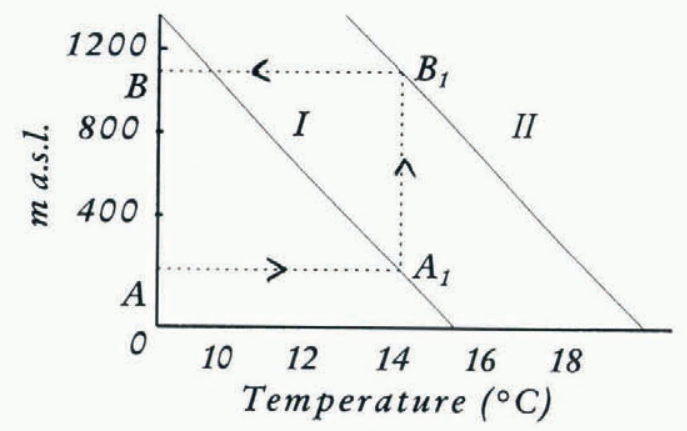

Fig. 5. The scheme of GTA profiles in the $2 \times \mathrm{CO}_{2}$ situation: I, temperature profile (modern data); II, the same for $2 \times \mathrm{CO}_{2} ; \mathrm{OA}$, height of glacier terminus for $\mathrm{I} \times \mathrm{CO}_{2} ; \mathrm{OB}$, the same for $2 \times \mathrm{CO}_{2}$.

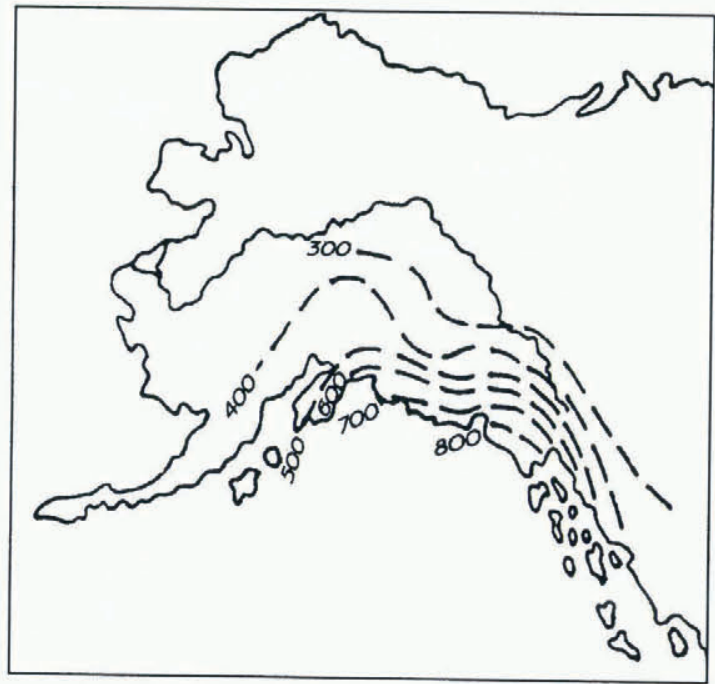

Fig. 6. Forecast values (meters) of $\triangle G T A$ for $2 \times \mathrm{CO}_{2}$ situation.

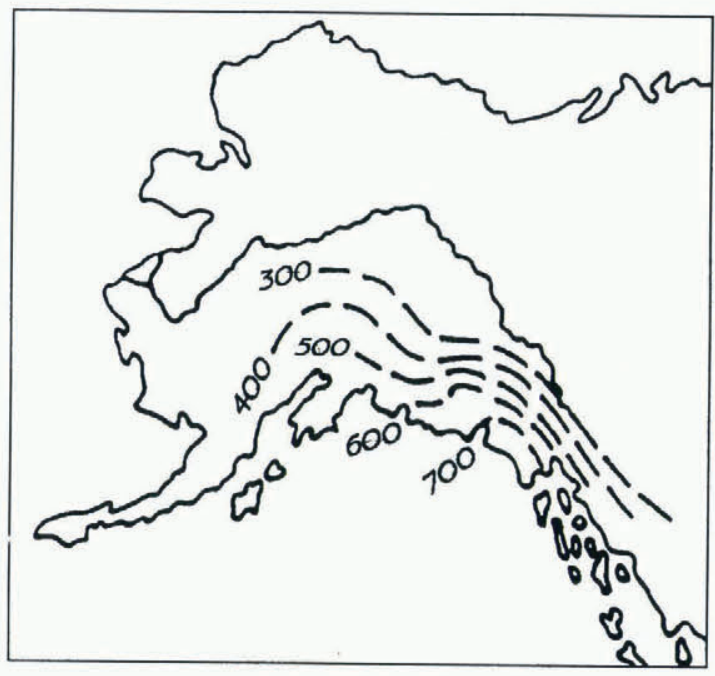

Fig. 7. Forecast values (meters) of $\triangle E L A$ for $2 \times \mathrm{CO}_{2}$ siluation.

will occur on the southern slope of the St Elias mountains, in the Fairwater Peak region and in the Muir glacier basin (Table 1, columns 2 and 7). The ELA shift will be more substantial in oceanic climate areas than in continental ones. The result corresponds to the worldwide regularity: ELA in oceanic climate regions due to more intensive precipitation is always lower and temperature at the ELA higher than in continental climate regions within any mountain-glacier country. Nevertheless, the absolute ELA values for glaciers in continental areas will remain higher.

In spite of such a considerable upward shift of the ELA, the predicted $T_{\text {sum }}$ values at the ELA will exceed those we have now (Fig. 8). They are expected to reach $6.0-7.5^{\circ} \mathrm{C}$ in the area of Pacific Ocean influence, a temperature that is not observed anywhere at present. Correspondingly, the ablation is to increase by 1.15-1.59 times (Table 1, column 6). Consequently a glacier melt runoff should increase under the predicted warming.

A relatively independent method is used to evaluate the amount of glacier melt runoff. It is based upon the results previously obtained by the authors for the above mentioned 12 regions of southeastern Alaska and the 


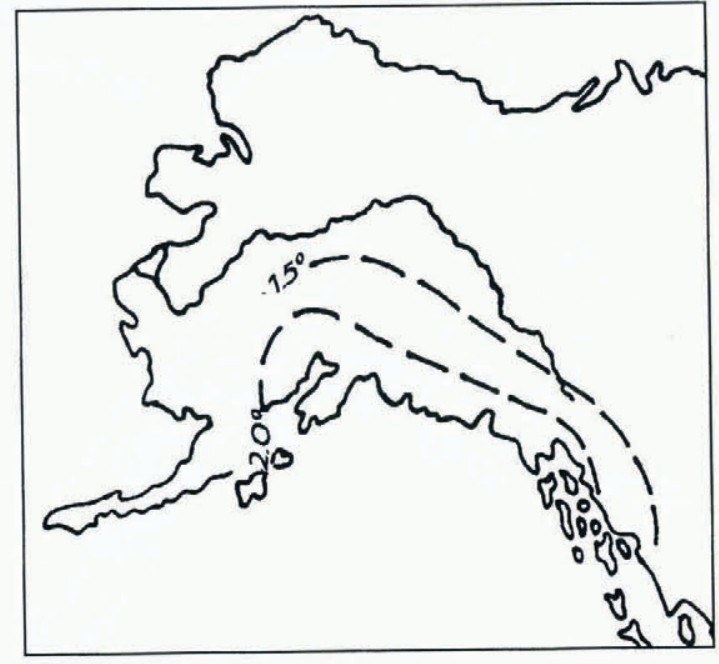

Fig. 8. Forecast increase of $T_{\text {sum }}$ at the ELA in the $2 \times \mathrm{CO}_{2}$ over the $1 \times \mathrm{CO}_{2}$ situation.

northern section of the Coast Range (Ananicheva and Davidovich, 1993). Equations of a multiple regression have been derived as follows.

$R_{\mathrm{gl}(i)}=F\left(T_{\mathrm{sum}(i)}, X_{\mathrm{sol}(i)}\right)$, where $R_{\mathrm{gl}(i)}$ stands for melt ice and snow runoff (in millimeters) for $i$ region. The equations use empirical data for melt runoff, summer temperatures and solid precipitation which correlate with absolute elevations. New $R_{\mathrm{gl}}$ values have been introduced by the substitution of climatic parameters with those predicted by the Wetherald and Manabe scenario for the $2 \times \mathrm{CO}_{2}$ situation. It is evident (see Table 1 , column 10) that the maximum $R_{\mathrm{gl}}$ increase will take place in the mountains of the Alaska Range: by 2.5 times on its "oceanic" slopes, by 2.1 times on the "continental" slopes. A considerable (though lesser) increase will occur within large glacier knots of the Chugach, Wrangell and Fairwater Mountains. A small $(10 \%$ or less) runoff increase will take place on the "continental" slopes of the Coast Range.

The ratio between $R_{\mathrm{gl}}$ in the $2 \times \mathrm{CO}_{2}$ situation and present $R_{\mathrm{gl}}$ (the information on runoff and climate parameters within the $1950-80$ period have been used) can be compared with that for the ablation (Table 1, columns 10 and 6 ). This fact indirectly confirms the reliability of the results obtained earlier by Ananicheva and Davidovich (1993). Nevertheless, we should note that the proposed method is not sufficient for calculation of absolute values of predicted $R_{\mathrm{gl}}$. This is because the changes of the parameters used in the equations, in particular, of $T_{\text {sum }}$, are beyond the confidence limits. Thus, the obtained values of $R_{\mathrm{gl}}$ should be considered only as an evaluation.

\section{CONCLUSIONS AND RESULTS}

1. According to the GFDL model, the forecast maximum increase of temperature (over $4^{\circ} \mathrm{C}$ ) will embrace the northeastern part of the Gulf of Alaska and adjacent areas, where glaciation is the most developed. While total precipitation will increase $1.2-1.3$ times within the studied area, the amount of $X_{\text {sol }}$ will not change substantially during the coming $2 \times \mathrm{CO}_{2}$ period, except for the Alaska Range and areas north of it, where $X_{\text {sol }}$ will rise 1.1 times.

2. With increase of $T_{\text {sum }}$ against a practically unchanged $X_{\text {sol }}$, the existing ELA and GTA will rise considerably. The biggest shift will occur on the southern slope of the St Elias Mountains, on Fairwater Peak and in the Muir Glacier area. Values of ELA shift, and their amplitudes in oceanic regions will be greater $(350-760 \mathrm{~m})$ than in continental ones $(300-400 \mathrm{~m})$. But the absolute ELA values for continental climate regions will remain higher than for oceanic ones.

3. The predicted $T_{\text {sum }}$ at the ELA $\left(6.0-7.5^{\circ} \mathrm{C}\right.$ in oceanic regions, $2.7-5.8^{\circ} \mathrm{C}$ in continental ones) will be considerably higher than it is today. No analogous temperatures at ELA can be observed on the Earth at present. Ablation will increase accordingly: 1.52-1.44 times the current maximum within the studied territory.

4. Glacier melt runoff $\left(R_{\mathrm{gl}}\right)$ will increase in the $2 \times \mathrm{CO}_{2}$ situation 2.5-1.0 times. Although it is estimated independently, the ratio between $R_{\mathrm{gl}}$ in the $2 \times \mathrm{CO}_{2}$ situation and its present value is nearly the same as for ablation.

5. Summarizing the above, we can state that the southeastern Alaska glaciation will not disappear under global warming but will be considerably displaced upward and glacier mass exchange will be more intensive.

\section{ACKNOWLEDGEMENTS}

We thank Professor V. M. Kotlyakov for moral support of this work. We also thank Yu. Kononov for assistance with figure drawing. Our special gratitude goes to the chief scientific editor, Professor D. R. MacAyeal, for his kind attention, help and encouragement and to Mrs E. Joyce for her helpful comments on the manuscript and editing.

\section{REFERENCES}

Ananicheva, M.D. and N. V. Davidovich. 1993. Prognoz izmeneniya talogo stoka s gor zapada Kanady i S. Sh. A. pod vozdeystviyem global'novo potepleniya [Prognosis of melt runoff changes for the mountains of west Canada and U.S.A. under the global warming]. Mater. Glyatsiol. Issled. 77, 50-58.

Bogdanova, E.G. 1976. Sposob rascheta doli tverdykh, zhidkikh i smeshannykh osadkov $\mathrm{v}$ ikh mesyachnoy norme [Method for calculation of solid and mixed precipitation share in their monthly standard]. Mater. Glyatsiol. Issled. 26, 202-207.

Budyko, M.I. and Yu. A. Israel, eds. 1987. Antropogennye izmeneniya klimata [Anthropogenic climate change]. Leningrad.

Cehak-Trock, H. 1958. Der feste Niederschlag im atlantischen Klimagebiet. Arch. Meteorol. Geophys. Bioklimatol., 8(3-4).

Davidovich, N. V. 1983. Okhlazhdayushcheye vozdeystviye gornykh lednikov umerennykh shirot [Cooling effect of mountain glaciers of the temperate zone]. Izv. Akad. Nauk SSSR, Ser. Geogr. 5, 7482.

Davidovich, N. V. 1984. Metodika sostavleniya kart teplovykh resursov $\mathrm{v}$ gorno-lednikovykh rayonakh mira [Method of compiling maps of heat resources in world mountain-glacier regions]. Mater. Glyatsiol. Issled. 50, $68-80$.

Kotlyakov, V. M., ed. In press. World snow and ice resources atlas. Minsk.

Krenke, A. N. and V.G. Khodakov. 1966. O svyazi poverkhnostnogo tayaniya lednikov s temperaturoy vozdukha [The relationship between surface ice melting and air temperature]. Mater. Glyatsiol. Issled. 12, 153-164.

Wetherald, R. T. and S. Manabe. 1988. Cloud feedback processes in a GCM. 7. Atmos. Sci., April, 1397-1415. 